\title{
Innovative approaches to foreign language teaching in Russian universities
}

\author{
Alla Bolshak $^{1}$ and Karina Voloshina ${ }^{1, *}$ \\ ${ }^{1}$ Kuban State University, 350040, Stavropolskaya str., 149, Krasnodar, Russia
}

\begin{abstract}
The article considers an innovative approach to teachingforeign languagesin higher learning institutions, whichispromptedby the forthcoming structural reform of higher education in Russia. The essence of this innovative method is peer learning. Integrating this method into foreign language classes has a number of advantages. First of all, it gives opportunities for students to share their experience and knowledge with each other without any concerns over the age difference. Then, it allows them to prove their language skills. Finally, it provides a sense of selfesteem: our data indicate that students feel more confident and self-aware when they demonstrate their expertise participating in cooperative learning tasks in a foreign language. So the primary concept of peer learning is that changing their knowledge students learn from each other.The article provides effective teaching techniques of implementing individual and group work through peer learning strategy and describes some cooperative learning situations which can improve students' proficiency in English.
\end{abstract}

\section{Introduction}

The article considers some aspects of structural reform of higher education proposed by President V.V. Putin in hismessage to the Federal Assembly inJanuary, 2020. It touches upon the innovative learning approaches aimed at formation of key cultural and professional competences of students who are trained for both established and emerging industries.By focusing on the undoubted importance of transformations of the education system in this countrynowadays we feel the urge toshare our experience in introducing some novelties in designing, conducting and managing more elaborate, but at the same time feasible approaches to teaching foreign languages, which bring together theory and practice. We assume that effective teachers should keep up with the latest developments in training methods and new trends, which will undoubtedly help them to organize proper classroom activities and make students demonstrate their best qualities.

This research has been undertaken to prove advantages of the innovative practices which are coming in importance in light of the new standards designed for higher learning institution in the Russian Federation. The need for modernization of the education model in

\footnotetext{
*Corresponding author: ksvoloshina@icloud.com
} 
Russia had become urgent long ago. Therefore, the issue under consideration contains a number of innovations meant to make learning programs more efficient and comprehensive. The rationale for this matter is that after graduating from university young people must possess relevant knowledge and competences which can allow them to become professionals with highly marketable skills. One of the key points of this reform is the so called "deferred choice" which provides an opportunity for students to choose a major after two years of studying for the first degree. It is assumed that by the third year at a higher learning institution they will gain a certain amount of knowledge and experience to decide on the career choice. As for the courses that count towards their degree, they are supposed to be completed during the following two years of studying.

Taking into account the forthcoming changes we came to the conclusion that the combination of knowledge of a foreign language with the basic skills of both professional and everyday communication will pay students real dividends in their working life in future. According to new tendencies in the labour market, a growing number of companies are no longer satisfied with specialist who have no good command of foreign languages, that is why those employees who in addition to their qualificationknowat least one foreign language are currently in demand because they have far more opportunities to have high performance ratings due to the following aspects:

- they can obtain specific information which is necessary for their work and use it in an efficient and timely manner;

- they can communicate with their foreign colleagues without an interpreter at any possible time and place;

- they can be aware of the latest achievements in the area they are involved in.

\section{Methods}

The research was done with the help of observation of the student response to teaching techniques based on a set of tasks whichprovide real-life situations when language can be used communicatively. This method involves describing students' attitude to the learning process and recording their progress and educational attainment in a special journal so that they can later be compared with the results they achieve upon a certain stage of languagelearning. When doing this work we also used the experimental method. We verified our conclusions by inventing assignments which made possible: 1) to determine the level of difficulty of the tasks offered; 2) to see if students are interested in obtaining new knowledge from each other; and 3) to understand how much they are motivated to carry on learning a foreign language in the long term.

The third method we used for research purpose was a self-report method. We made up a set of questions concerning the learning processand asked students either in person or in writing, which allowed us to collect a lot of relevant information rather easily and quickly. For example, students were supposed to explain what results they expected from these classes, what activities they liked most, what type of work they found more useful individual or group, what skills they would like to strengthen, etc. On the whole, due to this method we were able to make important conclusions as to student linguistic and nonlinguistic behavior. Being aware that the quality of questions affect the validity of the data obtained we avoided ambiguous wording and formulated them clearly and directly. The results obtained confirm the efficacy of this method. A detailed analysis of the data collected was discussed with our colleagues who teach psychological disciplines in our University. 


\section{Discussion}

It is a well-known fact that whatever the field of activity a person works in, they shouldprimarilybe self-organized and well-disciplined. Besides, being able to communicate with people of different personality types, make reasonable decisions, accept responsibility and be consistent also make sense. All these qualities influence appropriate work ethic and moral integrity of an employee. In this regard the techniques we propose can help students not only to master a foreign language, but also to improve their interpersonal skills and motivate them tobe open to new ideasandnever stop learning, which will contribute to their successful personal development. To have a thorough understanding of innovations in education, it is worth making a brief overview of the points of view on the nature of innovation.

To begin with,ÁronTörök, JózsefTóth, and JeremiásMátéBalogh assume that "innovation, like other goods or assets, can be produced based on the existing set of knowledge, the absorptive and adaptive capacities of companies together with the availability of new ideas" [1]. Sang M. Lee and SilvanaTrimi are sure that innovation must search for intelligent solutions to tackle major social ills, seek more proactive approaches to predict the uncertain future, and pursue strategies to remove barriers to the smart future [2]. Sarah Philipson pays especial attention to the forces behind the increased complexity of innovation, namely, shorter life cycles, lower direct production costs, intellectual property, knowledge transfer, and network economics [3]. For these reasons, "the discipline of innovation is one that is drawing more interest among many researchers in the world, therefore explaining its rapid growth" [4].

Now let us get down to considering innovations in education. According to Antonio L.Leal-Rodrígez and GemaAlbot-Morant, "the introduction and deployment of novel and fresh teaching ways that intend to enhance the students' ability to absorb knowledge involve attending to practical workshops and seminars, reading, analyzing and grasping case studies, relying on experience-based activities and learning by getting involved in simulations" [5]. Thomas Baumann, Kinsey Mantay, Alice Swanger, Gary Saganski and Sophie Stepke emphasize that "innovation in education will be immensely more successful if lessons learned innovation models and examples from industry are integrated into existing educational systems" [6]. Although there are a great variety of useful and prolific teaching techniques, the problem posed in this paper is still suggested for discussion.

There is no doubt that changes in all spheres of our life require professional specialists who would possess sufficient foreign language competence, so innovative student-based learning environment has to be redressed as a matter of priority. Suchenvironment, in preparation for well-qualified, well-educated and well-cultured specialists, characterized by various forms of pedagogical technologies, must be able to construct an important contract of the modern civilization. Proper combination of different learning systems leads to mutual enrichment in organization and maintenance spheres, increases professional experience effectiveness, supports fruitful application of new learning practices. What is more, it gives an opportunity to develop students' individual abilities and, consequently, improve their competence. In other words, students are taught to manage their own leaning process in addition to the learning process itself [7]. The complex technique to teaching English as a second language we offer is organized on the principle that the combination of the appropriate language course curriculum and enthralling tasks creates motivated students who have a genuine interest in obtaining new knowledge and experience. The essence of this innovative method is peer learning. This way of conducting classes is focused on the idea of mutual teaching when these or those learning activities are carried out for students by their groupmates in the class. 
There are several reasons why this approach is currently getting more and more significant. Firstly, exchanging knowledge students learn from each other more quickly and effectively. The thing is that firsthand knowledge of a savvy student who is willing to share it with others is better educational material for their peers than traditional explanation of conventional rules given by the teacher. Secondly, such way of organizing a classroom activity is less stressful - students feel free when performing the tasks they are offered. Thirdly, the teacher does not dominate in the classroom anymore because it is students who play the major role in the learning process. But it would be erroneous to think that teachers take a passive part in such classes. The teacher is a facilitator of such kind of activities s/se helps students follow the directions of the tasks, controls their use of language, and identifies their needs so that later this information can be processed when working out subsequent tasks. Moreover, to be able to conduct such lessons, teachers should have specialized classroom competence to make peer feedback a common learning practice. They have to engage in long-term planning regarding the content and structure of their lessons so that they are able to promote student learning and achievement successfully [8].

Fortunately, today we have a variety of resources which can make learning environment as interesting as possible. As for the teachershe/he must provide feedback and guidance in this process whereas students are expected to give adequate responses making progress in attaining their academic goals. As the following picture indicates, peer learning is easy to implement in the curriculum designed for students at the first level of education.

Individual work

Group work

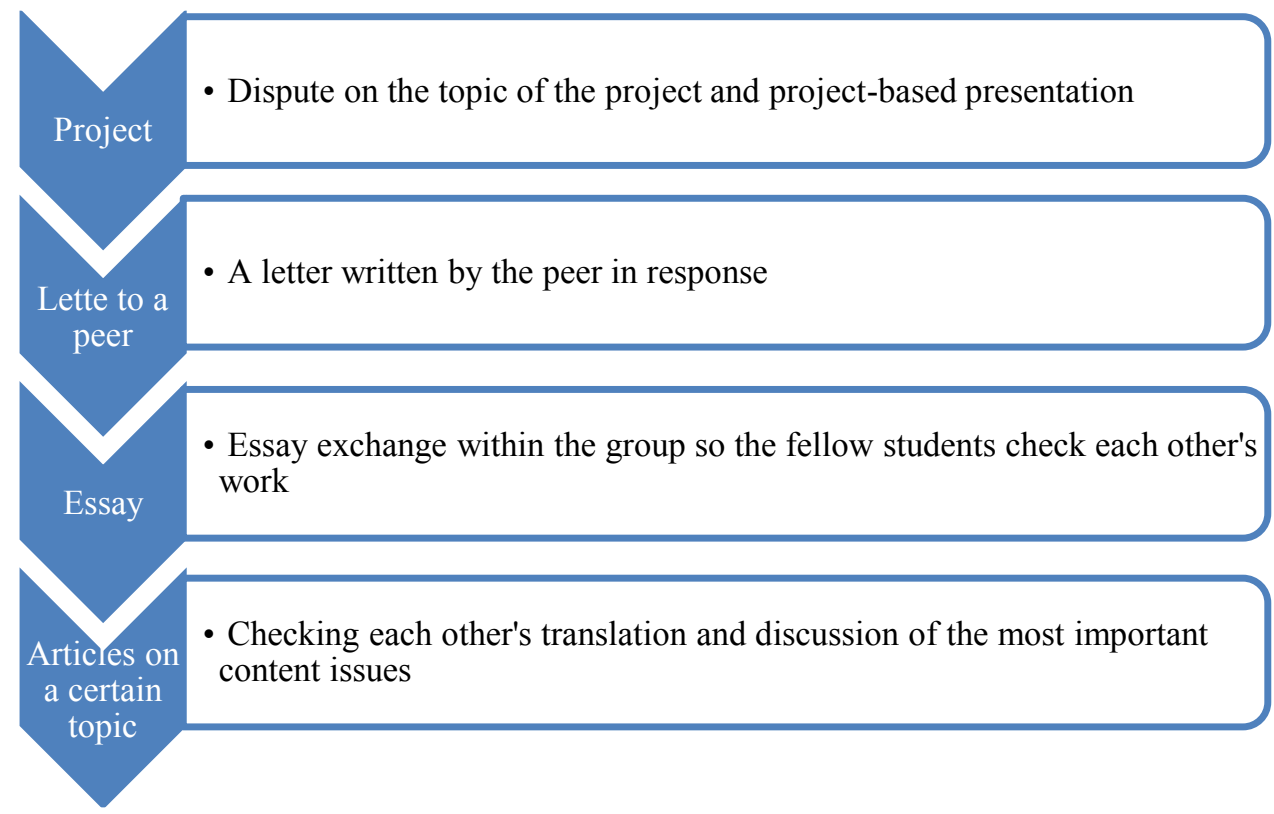

Fig. 1. Types of Work

Using the integrated approach to teaching Englishlet us consider some various workactivitiesin language classroom environment which stimulate and fosterlearning process considerably. Figure 1, presented above, illustrates different types of individual student work intended to improve some language skills and serve as "preliminary workout" before peer learning strategy comes into play. It should be noted that individualworkhelps 
students get creative autonomy through cognitive independence and self-educational abilities. As it is aimedat implementation of different tasks independently (project, writing a letter to a peer, essay and articles on a certain topic), the stress in such a case is unquestionably on responsibility for result, personal interest and management of informative process.

Forms of language-learning activity that often do not have a specific language-item focus are potentially long.Doing project workisdefinitely really creative thing, because firstly, it challenges students to thinkand work individually outside the classroom, secondly, it gives them a sense of achievement and, thirdly, it motivates them to get their own communicative competence as well as establish certain relationship within a group where peers may perceive knowledge gained through the project as a strong incentive for personal educational development and individual English language improvement.

Gradual flow from self-made project into group discussion through dispute and projectbased presentation makes the whole learning process much more sufficient and effective. Doing the project students practice their research skills, develop their literacy and critical thinking skills, master language fluency and accuracy. However, to achieve all abovementioned goals in creating a project is almost impossible without genuine desire, in other words, high motivation, which could stimulate, encourage and accelerate all learningprocess. The viable approach to the research is to have students investigate a group of questions related to the theme discussed.

For instance, if we deal with the issue where skills for success are examined, we can anticipate students' "investment" by giving them a few topics to tackle, such as Making good decisions orPeople you think would act as role models or you consider successful. When discussing education it would be appropriate to touch upon the following topics: Long-distance learning; advantages and disadvantages or Studying at University and working part-time: Is it a good idea? Ethical problems can be presented in topics devoted to family relationships, for example: Is it right to place the elderly in the nursing home if s/he hasyounger relatives? or How to cope with rising divorce rate. The issues connected with health and well-being of the population are also worth our attention. In this respect such topics as Genetically modified foods: is it reallyway to fight world hunger?OrCosmetic surgery: is it a fashion trend or new realia? would be of great interest for both male and female students.

Thus, it is important to present project topics, which tap into the students' intrinsic motivation both at the stage of initiating and self-sustaining. It is difficult to predict what kind of topics any particular student will find worthwhile for their own sake, but we can define the direction that students consider essential for them personally and then influence their ownwish to share the information with the groupmates. In this case, sharing and, as a result, learning from each other students do not only unconsciously contribute to the mutual activity, but also evaluate their own learning engagement. Since students "may experience difficulties adjusting to various elements of the learning context, a teacher, who is open, friendly, human, respectful, honest and authentic will always play an essential role in creating a positive learning environment [9]".Most importantly, learning starts being mutually beneficial, because peers having no power over each other provide intangible emotional supportand create a productive collaboration and communication.

Visual nature of the project through project-based presentation strengthens students' involvement in the learning process. Upon completing this task students are required to make some comments on topics discussed and they mainly succeed in giving talks and sharing their opinions. At this stage, peers start close interaction based on two types of skills involved in a discussion: presentationskills and participation skills. Students enjoy being a part of a group, they are able to see the result of their collaborative work and they have a clear understanding of what they should look for in their peers' work. The time 
management plays a very important role in such events. [10]. Moreover, the evaluation process itself becomes an opportunity for spontaneous interaction and, consequently, further language improvement.

Another form that we find particularly relevant to our teaching practice is writing a letter to a peer. This type of personalized activity can be really effective in cross-module learning, because senior students are more likely to guide junior students and encourage them to give a productive feedback and master revision. One reason why this approach, in principle, is more interesting than others is the fact, that the use of students' own personal experience, opinions, ideas and feelings becomes an element of personal "investment": peers are "giving «themselves to each other, and finding out real information about one another. It does not only raise the level of attention to what is written, but also tends to contribute to an atmosphere of warmth and friendliness between each other. Another reason to support this approach is a teacher's role. In this situation the teacher plays a part of a moderator/facilitator and he/she does not have an opportunity to monitor their students' work or check every letter. So, students write and exchange letters with the peers independently without any teacher's control or help, which, undoubtedly, causes no embarrassment or distress and leads to gradual enhancement of language communication confidence.

When implementing this approach in classroom environment there is a point in having an element of surprise and,in this case, writing a letter to an unfamiliar peer can be a good idea.The only thing that the students are aware of is their potential peer's name or a nickname, so it makes students be more interested in getting useful information about a person they don't know. The letters written outside the classroom hours are put in a small box and "exchanged" independently for a while.Certainly, it takes some time to swap information and get to know one another virtually. In the end, when students acquire quite a lot of information about their peers, some informal classroom activity is held.

To some extent, this is theclimax of the work done before. All students (juniors and seniors) are invited to join a classroom "party" where all peers are introduced to each other by telling a few facts about their penal. As the students do not know one another personally, it would be quite interesting and exciting to organize an activity where students could figure out who their peers are. Since their English level ranges from pre-intermediate to upper-intermediate, students who have low level of proficiency will benefit from doing this task very much, because they are not confused about what they have to be doing. Along with that, students with a higher level of proficiency also benefit from such collaboration since they deepen their skills and knowledge, they learn to instruct others and they sharpen their cognitive process of explaining tactics.

At the same time they take an opportunity to learn from others and simultaneously create the environment which comprises sharing knowledge, ideas and experience between participants. In fact, the way students interact with each other influence their learning process [11]. When students are involved in the activity, which can be described as highly motivated, their concentration is very deep, all their minds and bodies are engaged, they are not worried about failing and time passes very fast. In this case it is important to pay attention to the degree of student's own involvement and teacher's mediation [12]. So, based on cross-module learning, the capacity of being activated in the process provides integrated skills practice and allows the teacher to design a lesson where peer learning strategy would become mutually fruitful. It is obvious, that students acknowledge the importance of face-to-face peer interactions [13].

The next activity we have been applying in our classes with undergraduate students is writing an argumentative essay. The «learning-by-doing" approach is a really essential component of any language and professional development course. Traditionally, writing an argumentative essay is an appropriate way of introducing principles of English writing 
discourse and rhetoric. In addition, an essay is a powerful tool with which we can convince the reader about some point of view or take a position on a controversial issue and present evidence in favor of our position. So, students can express their opinions and thoughts by speculating on such issues as:

1. Why are modern humans fast losing their intelligence?

2. What are the most widespread ways to ruin your health?

3. Ethics and values of modern politicians: did they change much since ancient times?

4. Is it possible to preserve language purity in the age of globalization?

5. The most relevant age to get married.

6. How to learn to maintain a peaceful state of mind.

7. 'Faithful friends are gifts from Heavens - whoever finds one has found a treasure' (Anonymous).

8. How to survive disasters.

We strongly believe that choosing topics connected with students' professional field of education is of utmost importance, because, in this case, all learning process is reoriented from language-centered to knowledge-centered reflecting the socio-cultural reality, where the students should express and develop themselves as well as get considerable prospects for professional and personal growth. In the end students are supposed toexchange their written research work with peers within a group. While working in a group with their peers, students have an opportunity to compare their pieces of writing and draw objective conclusions as to how consistent, coherent, logical and clear their peer's essay is.

It is worth mentioning that nowadays there is a growing need for a new type of a professional - an educated person, who in addition to the traditional skills and competences, required in professional field, would have more universal or cross-disciplinary characteristics. Therefore "students and teaching staff alike are highly aware of the asset that good professional skills represent in the conditions of the contemporary world [14]". Among those skills are an ability to critically analyze each other's experience, create multiple alternatives and choose the most appropriate ones for a particular professional situation, the ability to network and work in groups, the ability to learn and share, etc. These abilities include establishing constructive and meaningful relation with peers, trying to understand and consider their position rather than impose their own truth on the perspectives, recognizing differences in opinions, approaches, strategies and learning from others, managing disagreements and conflicts and sharing their own experiences with others in a mutually enriching way. In this respect, learning through independent writing and further group discussion helps students understand writing as a peer learning process, increase their sense of mastery and improve their own language competence.

Teaching and learning English as a foreign language certainly places us in that mode where we have to generate an innovative approach based on cooperative learning that becomes a sustainable practice in language classroom environment. Accordingly, incorporating article reading into peer learning process could give us an opportunity to activate all group member participation simultaneously and bridge an information gap between peers. An information gap exists when one peer knows something that the other doesn't, and they need to communicate in order to convey the information.

In this regard, swapping the information taken from the article students get into a situation of knowledge compensation, so the transmission of new ideas from one peer to another occurs in real language-based transaction; and when this factor is built into a classroom language-learning activity, the effect is to add a feeling of purpose, challenge and authenticity which boost students' interest. On the one hand, when students search for an article on a certain topic, read and translate it individually, and later discuss the most important content issues in groups, their interest, enjoyment, engagement and performance increase and their productive and interactive learning environment increases students' 
motivation. At the same time, it is really helpful if the students know that their effort will be assessed, both on individual and group level. So, at this stage, the teacher's role is slightly changing. It becomes more tutorial and mentoring. When exchanging the ideas, learning some new facts, peers remove the information gap and, consequently, become more mature, knowledgeable and experienced in the professional field. Thus, combination of different activities in language classroom environment, basically, provides integrated skills practice and, as a result, increase personal academic achievement.

Of special interest is the task concerning the translation of the articles chosen. Students are supposed to render them in their native language and exchange their works with their groupmates. To assess each other's work students should take into consideration the following aspects:

1. Is the translator familiar with the subject matter of the ST?

2. Did he identify correctly its genre or functional style?

3. Did he work out an effective translation strategy?

4. Did he use additional material to grasp the sense of the ST?

5. Did the translator identify culture-related items which often require correct interpretation? Did he provide them with translator's commentaries?

6. Did he employ appropriate lexical translation techniques?

7. Did he resort to lexical and grammatical transformations and contextual replacements?

8. Did he cope with two syntactical structures - English and Russian - which differ in many aspects?

9. Does the TT comply with the standard conventions in the TL punctuation?

It is important to note that peer assessment is an indispensable part of the learning strategy we are discussing: relying on our observations we came to the conclusion that evaluating each other's performance during learning activities students not only improve their language comprehension, they also broaden their minds in various spheres of life. To gain maximum benefit from group work the classes when students work in partnership are recommended to be recorded so that the participants of the event can watch it later and analyze in detail the course of the lesson. As a matter of fact, this approach has advantages for both - teachers and students. The former can determine the accuracy of the structure of the task, its informative component and the level of student preparation for such kind of work, whereas the latter have a great opportunity to evaluate the strengths and weaknesses of foreign language proficiency and their willingness to perform different tasks together with their groupmates.

Describing several practical approaches currently used in our foreign language teaching and examining some particularintegrated practices in peer learning enable us to assess the relevance as well as value of this strategy in language classroom environment since the approaches appliedcan be implemented in various ways and it is sometimes difficult to say which one is preferable. In this connection we agree with Mari Murfonen and her coauthors who write that "the most important indicator of the quality of learning is how rich and well organized the knowledge structures are" [15]. Luckily, innovative changes in education cause emerging numerous mechanisms in learning environment, so applying different approaches that could lead to good performance and effectiveness, innovative teacher/student work and developed reflective objective attitude is steadily growing.

\section{Results}

Language learning approaches, presented in our research, have several implementation stages which follow a predictable sequence. Each stage contains a clear goal and involves achieving an outcome intended to provide rich learning opportunities which could promote peer learning process. Figure 2attempts to characterize the stages through which some 
learning activities most commonly proceed and also the order in which these stages could occur.

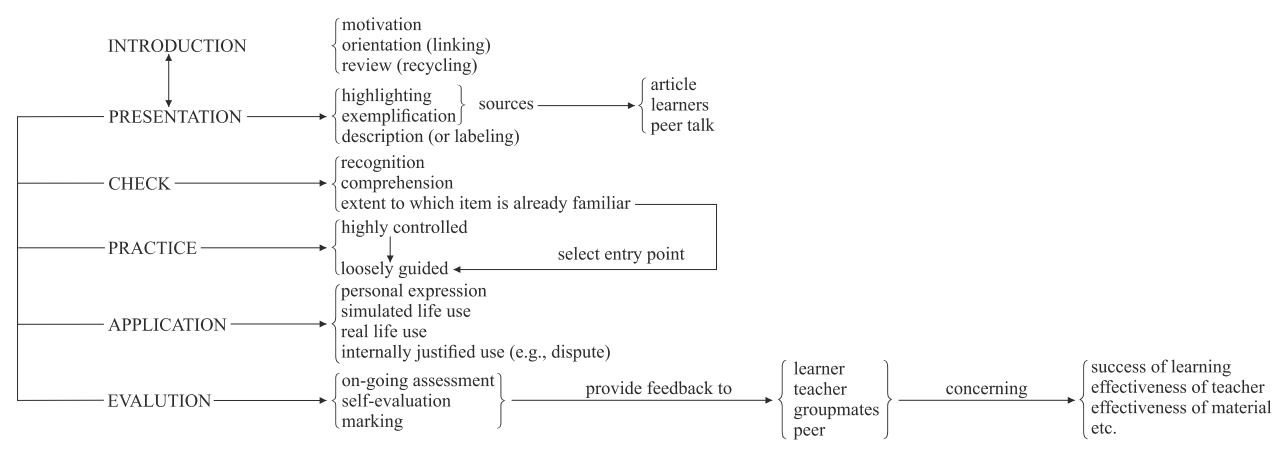

Fig. 2.Peer Learning Stages

The model presented above demonstrates some approaches which make the whole language learning process much more meaningful and memorable. The activities incorporated into peer learning strategy provide various interaction practices and contribute to constructing new language concepts. What is more, students' existing knowledge, experiences, potential gaps in content and skills are identified and evaluated through collaborative interest and challenges. Experience suggests that employing peer learning in a foreign language class effectively and efficiently requires:

1) careful advanced planning;

2) designing tasks in which language could be used communicatively;

3) selecting interesting and up-to-date themes which can be of great interest to students (on this stage the teacher may rely on the opinion of his/her class who can determine the issues which are important to them);

4) providing students with clear instructions to avoid any misunderstanding when carrying out this or that task;

5) encouraging them to explore new tendencies which characterize our society.

6) Obviously, adhering to these requirements will help to achieve successful student outcomes.

In our opinion, peer learning can increase student interest in further improving their language skills as well as getting professionally oriented knowledge, which willenable them to achieve success in the long run.As a relatively new teaching method, it requires further investigation which should rely on the interdisciplinary approach. Research has shown that to organize productive peer learning process we should take into account not only linguistic and pedagogical aspects of the activity; we should also apply reliable and relevant data derived from such scientific disciplines as psychology, physiology, statistics, and others. We strongly believe that it is impossible to create and implement an appropriate learning strategy without knowing student linguistic potential, their cultural awareness, their mental and physical abilities, and many other factors. As for the future lines of our research, we think it would be logical to get down to a new stage of language teaching implicationsthat is peer teaching. This method is based on a learner-centred approach to passing on knowledge and skills to students by their groupmates. On this account, we suggest deeper and more detailed investigation of this practice.

All things considered, we believe that promoting and supporting new trends in higher education will be a great stimulus for interaction between experts involved in the process of improving teaching and learning programs in Russia so young people after getting a degree can succeed not only in their personal life but in a career as well. And from this viewpoint, 
it is necessary that a more comprehensive study of new methods of teaching foreign languages should be performed.

\section{References}

1. Á. Török, J. Tóth, J. M. Balogh, Push or Pull? The nature of innovation process in the Hungarian food SMEs.Journal of Innovation \& Knowledge, 4, 234-239 (2019)

2. S. M. LeeSilvana, TrimiInnovation for creating a smart future. Journal of Innovation \& Knowledge, 3, 1-8 (2018)

3. S. Philipson, Sources of innovation: Consequences for knowledge production and transfer.Journal of Innovation \& Knowledge, 5, 50-58 (2020)

4. C. A. Cancino, J. M. Merigó, F. C. Coronado, A bibliometric analysis of leading universities in innovation research. Journal of Innovation \& Knowledge, 2, 106-124 (2017)

5. A. L. Leal-Rodríguez, G. Albort-Morant, Promoting innovative experiential learning practices to improve academic performance: Empirical evidence from a Spanish Business School. Journal of Innovation \& Knowledge, 4, 97-103 (2019)

6. T. Baumann, K. Mantay, A. Swanger, G. Saganski, S. Stepke. Education and Innovation Management: A Contradiction? How to Manage Educational Projects if Innovation is Crucial for Success and Innovation Management is Mostly Unknown.Procedia - Social and Behavioral Sciences, 226, 243-251 (2016)

7. T. Seufert, The interplay between self-regulation in learning and cognitive load. Educational Research Review, 24, 116-129 (2018)

8. L. Bardach, R. M. Klassen, A systematic review of teacher guidance during collaborative learning in primary and secondary education. Educational Research Review, 30, 100312 (2020)

9. M. Cozma, The Challenge of Teaching English to Adult Learners in Today's World.Procedia- Social and Behavioral Sciences, 197, 1209-1214 (2015)

10. Z. Polkowski, R. Jadeja, N. Dutta, Peer Learning in Technical Education and it's Worthiness: some facts based on implementation. Procedia Computer Science, 172, 247-252 (2020)

11. A. van Leeuwen, J. Janssen, A systematic review of teacher guidance during collaborative learning in primary and secondary education. Educational Research Review, 27, 71-89 (2019)

12. N. Bulle, Student's activity and development: Disentangling secondary issues from the heart of the matter, Educational Research Review, 27, 56-70 (2019)

13. L. Pushkareva, M. Pushkarev, Experience economy in the system of culture and education. E3S Web of Conferences, 135, 04070 (2019) doi: $10.1051 / \mathrm{e} 3$ sconf $/ 201913504070$

14. D. Rus, N. Medrea, Developing Communicational Abilities in Professional Environments Through English Language Teaching. Procedia-economics and Finance, 3, 1161-1164 (2012)

15. M. Murtonen, H. Gruber, E. Lehtinen, The return of behaviourist epistemology: A review of learning outcomes studies. Educational Research Review, 22, 114-128 (2017) 